\title{
Play vs exergaming: A conceptual analysis as to why exergaming is not play
}

\section{Maria Kosma ${ }^{1}$}

School of Kinesiology, Louisiana State University, Baton Rouge, LA, USA.

\begin{abstract}
The fields of kinesiology and public health promotion have significantly invested in the potential for online, digitally mediated exergaming to promote higher levels of physical activity and so to reduce disconcertingly high levels of obesity in the USA. The proponents of exergaming attempt to tie exercise to play in order to make exercise fun and sustainable over time. Drawing on Huizinga's Homo Ludens, the purpose of this concept-based paper was to conceptually analyze the motivational resources provided by true play in contrast to the engineered instrumental design of exergaming. The analysis furthermore explains the disappointing results of studies to date on the effects of exergaming. According to Huizinga, play is undertaken for its own sake, for the lived experience of joy, tension, creativity, and release. In contrast, exergaming emphasizes measurable objectives to lose weight and reduce morbidity and mortality rates. This pressure to meet biological needs appears not to be enjoyable like in true play, and, ironically, exergaming is more likely to harm rather than improve users' health. Physical activity experts need to emphasize the true elements of playful movement for the felt experiences it can afford, including artistic expression, dance, and recreational games at schools, neighborhoods, and local parks.
\end{abstract}

Keywords. Huizinga's Homo Ludens, play for its own sake, play vs. exergaming.

\section{Introduction}

There is tremendous concern in health circles about the on-going pernicious effects of persistently high levels of obesity on the health of the American people (Trust for America's Health [TFAH] 2020). Several public agencies like the National Institutes of Health (NIH) and Centers for Disease Control and Prevention (CDC) and private businesses such as the many weight loss centers and programs have invested enormous resources in seeking to identify effective interventions that can successfully stimulate or motivate people to lose weight (Tchang, Saunders, \& Igel, 2021). Virtually all programs are based on changing people's diets (to reduce calorie consumption) and/or increasing levels of physical activity (to increase energy expenditures) (TFAH 2020). Given the rising obesity rates in the USA (TFAH 2020), there has been increasing interest in the potential for "virtual" on-line programs, generically referred to as "exergaming," to increase and sustain users' interest and motivation to engage in regular sufficiently intense physical activity towards the goal of reducing obesity rates (Thompson, 2018). The proponents of exergaming attempt to tie exercise to play in order to make exercise fun and sustainable over time (Sall \& Grinter, 2007). The physical activity technology market is also highly profitable. In 2020, the revenue of the worldwide digitized fitness industry has been $\$ 21,92 \mathrm{~m}$, over $\$ 7 \mathrm{~m}$ up from 2017 $(\$ 14,606 \mathrm{~m})$ (Statistica, 2020).

Drawing on Huizinga's (1950) seminal book, Homo Ludens, the purpose of this concept-based paper was to conceptually analyze the nature of true play; to contrast that with the prime characteristics of exergaming; and thereby explain why exergaming fails to accomplish its ostensible goal of making long-term exercise participation playful and enjoyable. The paper starts with the definition of play, games, and exergames to clarify these concepts and justify the use

M. Kosma, e-mail: mkosma@lsu.edu

Received: October 26, 2021 - Accepted: December 07, 2021 - Published: December 31, 2021

To Cite: Kosma, M. (2021). Play vs exergaming: A conceptual analysis as to why exergaming is not play. Turk J Kinesiol, 7(4), $141-151$. DOI: $10.31459 /$ turkjkin.1015139 
of Huizinga's holistic and comprehensive approach on play as a freely chosen activity for its own sake. Afterwards, Huizinga's definition of play is delineated, including elaboration on five primary non-reductive characteristics associated with his fecund definition. After describing and explaining these five characteristics, we go on to show how exergaming fails to meet the criteria of true play, and thus, fails to mobilize or tap into the motivational resources that people find when they engage in play. We conclude with reflections on the need for restoring play as an integral part of leading well-balanced lives.

\section{Play, Games, and Exergames}

A group of friends are playing basketball at the park. Children are racing their parents while they are riding their bikes at a nearby neighborhood. Elementarylevel students are playing tug at the schoolyard. A group of friends is playing tennis for leisure. Adolescents exhibit swimming skills in the sea during vacations. College students perform dances and theatrical performances during a university event organized by a dramatic arts department. Spectators are gathering to watch an artistic gymnastics competition during the summer Olympic Games. All these phenomena have something in common, which is their play element. Many scholars throughout the centuries have attempted to define play and games. Psychologists like Berlyne (1960) view play as an emotional and physical activity that is fun and exciting. Others view play as a transformative phenomenon where people can be in a state of "flow", completely absorbed in the task at hand while they lose track of time, external distractions, and personal responsibilities and worries (Csikszentmihalyi, 2008). Play is also viewed as an escape from work, a form of individual action and interaction with others, objects, and their surrounding world, or a cultural format that involves expressions of traditions and history such as different game events (Bakhtin, 1981; Goffman, 1974). Regardless of the numerous attempts to reduce play to a distinct definition and compare it with its many forms like games, the overall consensus is that having a concrete definition of play is impossible. Using a reductive approach in the concept of play contradicts its nature, in that play should not be objectified; it is a freely chosen activity; a respite from the routine and work pressures (Aarseth, 2017; Henricks, 2008; Huizinga, 1950). In fact, Aarseth (2017, p. 1) argues that play and games should be viewed "as a perspective and not as an object or an activity." As long as "the phenomenon is interesting as ludic", then it is play regardless of the type (e.g., organized games or recreational activities with family and friends) (Aarseth, 2017, p. 1). In his masterpiece Truth and Method, Hans-Georg Gadamer (1975/2012) exemplified that play is not an object; it has its own essence and significance. The mode of being of play is not the experience, play mode, and perspectives of the player; rather, it is the experience of play for its own sake. Play is orderly, and the to-and-fro movement has a unique nature that attracts the player. The tactics of the player to succeed at a game are not "the attraction of the game... What holds the player in its spell, draws him into play, and keeps him there is the game itself" (Gadamer, 1975/2012, p. 106). The experience of play should be a sense of ease and relaxation without any strain. "The structure of play absorbs the player into itself, and thus frees him from the burden of taking the initiative, which constitutes the actual strain of existence" (Gadamer, 1975/2012, p. 105).

Based on the above brief summary, play cannot be reduced to a specific structure; it is a free and unique phenomenon expressed as an end in itself. Therefore, this paper's philosophy will be based on "one of the greatest books on the subject of play: John Huizinga's Homo Ludens" (Henricks, 2008, p. 159). In agreement with Henricks (2008) and others (e.g., Rodriguez, 2006), Huizinga (1950) holistically captures the free essence of play as an end in itself. Although Huizinga (1950) discusses certain elements of play, he makes it clear that those elements are not reductive by any means; play cannot be objectified - its uniqueness and meaning relies on the experiences it can afford.

Before embarking on Huizinga's philosophy of play, it is important to define exergaming, which will be later contrasted to Huizinga's true play. Exergames are active video games that combine exercise or physical activity with play (Bogost, 2007). The proponents of exergaming attempted to tie exercise to play to increase motivation towards sufficiently rigorous long-term physical activity to reduce obesity levels (Sall \& Grinter, 2007). Exergames typically require screen use whereby the player needs to move their body to the directions of the screen in order to play or win the game (Benzing \& Schmidt, 2018). Exergames can be played individually or in groups and they may require exercise equipment (e.g., exercise bikes connected to computer games, dance pad mats for Dance Dance Revolution, or motion sensors for Nintendo Wii) (Benzing \& Schmidt, 2018). They are 
typically marketed by the video gaming industry, including Nintendo and its major competitor, Microsoft's Xbox and Sony's PlayStation consoles (Handrigan, 2013). Exergames are being marketed to all age groups and a variety of settings, including fitness gyms and clubs as well as physical education classes (Resnick, 2012). Several concerns have emerged since their inception, including their failure to capture the diverse and complex experiences (e.g., skill, fitness, and interactive aspects) that can be afforded within a real play setting like in tennis and physical education (O'Leary et al., 2011; Pedersen, Cooley, \& Cruickshank, 2017). Other concerns include exergame boredom and failure to sustain fun and playful long-term physical activity participation (Baranowski, 2017; LeBlanc et al., 2013; Paw et al., 2008; Staiano et al., 2017). Although to our knowledge the direct effects of exergaming on screen addiction are unknown, in a recent study screen addiction was more common for entertainment and gaming than for work and professional networking. Most importantly, screen dependency for entertainment and gaming drastically linked to different types of stress, whereas screen use for work and professional networking was life satisfying (Khalili-Mahani, Smyrnova, \& Kakinamihas, 2019). Therefore, it is possible that exergaming may lead to screen dependency and its related negative consequences, including emotional, physical, and cognitive health issues (Kosma \& Buchanan, 2018, 2021).

Following this brief discussion on play, games, and exergames, in the below sections the notion of true play will be described in detail using Huizinga's masterpiece, Homo Ludens (1950). His holistic and comprehensive philosophy of play will then be contrasted to the engineered, mechanistic, and instrumental design of exergaming. Contrary to the proponents of exergames to tie them to play for increased fitness and decreased obesity, exergames do not meet the true elements of play; and thereby they have failed to accomplish their very goal of increasing playful and fun long-term physical activity participation.

\section{Definition of Play by Huizinga}

In his timeless book Homo Ludens, Johan Huizinga (1950, p. 13) offers a rich definition of play as follows:

"Play is a free activity standing quite consciously outside 'ordinary' life as being 'not serious,' but at the same time absorbing the player intensely and utterly. It is an activity connected with no material interest, and no profit can be gained by it. It proceeds within its own proper boundaries of time and space according to fixed rules and in an orderly manner."

Rodriguez (2006, p. 1) paraphrases and explains Huizinga's definition as follows: "play [is] a free and meaningful activity, carried out for its own sake, spatially and temporally segregated from the requirements of practical life, and bound by a selfcontained system of rules that holds absolutely"

Following from his own definition, Huizinga identifies five key elements of play. Based on Huizinga, play:

- Is a voluntary, freely chosen activity; it is devoid of biological function or social purpose. It serves no practical task.

- Is not ordinary life: it is an escape from the routine, inviting creativity and imagination.

- Has a specific time and place (e.g., playground) outside ordinary life within a socio-cultural and historical context.

- Creates rules and order to be followed outside ordinary life; thus, it is enjoyable.

- Creates tension, reflecting its unpredictability and moral value.

In the following section, we elaborate on each of these five characteristics.

\section{Key Characteristics of Play by Huizinga}

\section{Play is non-purposeful}

Based on the first characteristic, play is an enjoyable and freely chosen activity - "it is in fact freedom" (Huizinga, 1950, p. 8). It takes place as an end in itself - for sheer joy - and it cannot be forced or instituted (Huizinga, 1950; Vygotsky, 1978). It is nonpurposeful, non-materialistic, not intended to accomplish a practical task. It is irrational in the sense that it is not aimed at identifying the most efficient means to a given externally defined end. It is not supposed to fulfill a biological or social function. Although Huizinga highlighted cultural and societal expressions in play (human evolution via play, 
including games and festivals), he did not view play as a way to achieve some other goal, such as fulfil physical, social, and emotional needs. Rather, he viewed play as an end in itself, practiced for its own sake. Physical, social, and emotional aspects are inseparable from play and incommensurable - they cannot be separated from the whole experience and measured (see also Gadamer, 1975/2012). Play is time-out, free from the pressing immediate essential needs. Huizinga (1950) writes the following:

"Play to order is no longer play: it could at best be but a forcible imitation of it. By this quality of freedom alone, play marks itself off from the course of the natural process.... The need for it is only urgent to the extent that the enjoyment of it makes it a need. Play can be deferred or suspended at any time. It is never imposed by physical necessity or moral duty. It is never a task. It is done at leisure, during 'free time'”' (pp. 7-8).

"In play there is something 'at play' which transcends the immediate needs of life and imparts meaning to the action. All play means something. If we call the active principle that makes up the essence of play, 'instinct', we explain nothing; if we call it 'mind' or 'will' we say too much. However we may regard it, the very fact that play has a meaning implies a nonmaterialistic quality in the nature of the thing itself" (p. 1).

"Play continually confirms the supra-logical nature of the human situation, .... We play and know that we play, so we must be more than merely rational beings, for play is irrational" (pp. 3-4).

Huizinga (1950) explains that play is irrational because it is not only a human phenomenon. Animals play like children do; they have fun; they enjoy the activity; they pretend to be angry; they fight but they do not bite because biting spoils the game (Burghardt, 2005; Huzinga, 1950). In fact, animal play originated before the existence of human civilization and culture:

"Since the reality of play extends beyond the sphere of human life it cannot have its foundations in any rational nexus, because this would limit it to mankind. The incidence of play is not associated with any particular stage of civilization of view of the universe. Any thinking person can see at a glance that play is a thing on its own, even if his language possesses no general concept to express it. Play cannot be denied. You can deny, if you like, nearly all abstractions: justice, beauty, truth, goodness, mind, God. You can deny seriousness, but not play" (Huizinga, 1950, p. 3).

"Huizinga sometimes writes that play is "free", by which he means that the fundamental motive of play is the experience that it affords. We do not characteristically play to fulfil a practical task; we play for the sake of the lived quality that attaches itself to the act of playing" (Rodriguez, 2006, p. 1). It is the play experience that captivates the player and keeps her/him engaged in the activity. As Gadamer puts it, "the purpose of the game is not really the solution of the task, but the ordering and shaping of the movement of the game itself" (Gadamer, 1989, p. 97). The player at play can be in a state of flow, whereby they are totally absorbed in the task at hand. It is as if the player loses track of time and is entirely immersed in the experience (Csíkszentmihályi, 2008). During the play experience, body and mind act in unison (flow-like state), bringing the player in a state of ecstasy and joy like in dancing, jumping, swinging, and "flying" (being above ground) (Kosma \& Buchanan, 2021; Kosma \& Erickson, 2020a; Kosma et al., 2020, 2021; Lloyd, 2016; Merleau-Ponty, 1945/2014; Sheets-Johnstone, 2003). This inherent nature of play contradicts function-centered theories, which describe "play as a tool for the satisfaction of a biological or social need. This need is extrinsic to the explicit aims and rules of playing. The internal structure of play is only contingently connected to its putative function. The claim that playing offers a psychological compensation for some deep-rooted frustration, for instance, implies that playing could in theory have been replaced by some other behavioral technique capable of fulfilling the same function. This function is only a subsequent effect derived from playing, not an internal quality of the experience itself" (Rodriguez, 2006, p. 3). When participating in playful movement like dancing, physical and emotional sensations and experiences (e.g., becoming skillful and stronger or experiencing feelings of flow, elation, and ecstasy) are part of the inherent quality of the dance experience; these elements are inseparable from the action and incommensurable (i.e., they cannot be summed up to some value). Functioncentered theories are utilitarian in nature, trying to identify and separate certain functions (e.g., psychological or physiological) from the action itself 
in order to measure them. "For this reason, any function-centered theory necessarily fails to explain why people play" (Huizinga, 1950; Rodriguez, 2006, p. $3)$.

Sartre also exemplified that the action of play is inherent in nature, part of human existence and freedom:

"A person's freedom is also their anguish... the function of the act (play) is to make manifest and to present to itself the absolute freedom, which is the very being of the person... the desire to play is fundamentally the desire to be" - part of our existence and consciousness (Sartre, 1943/2003, p. 602).

\section{Play is not ordinary life}

Based on Huizinga (1950), play is not ordinary life, which reflects its second characteristic and reinforces its free and intrinsic element. Play is a stepping out of the routine, occurring in an imaginary world, which is immensely enjoyable. The pretending nature of play is highlighted below by Huizinga (1950, p. 8) when he described a father's story regarding his boy at play:

"He found his four-year-old son sitting at the front of a row of chairs, playing trains. As he hugged him, the boy said: "Don't kiss the engine, Daddy, or the carriages won't think it's real."

The pretend quality of play does not prevent it from being serious. "In play, we may move below the level of the serious, as the child does; but we can also move above it - in the realm of the beautiful and the sacred" (Huizinga, 1950, p. 19). In certain performances, such as dances, festivals, theatrical plays, and sports play can be lifted above seriousness: "it can rise to heights of beauty and sublimity that leave seriousness far beneath" (Huizinga, 1950, p. 8).

\section{Play has a specific time and place outside ordinary life}

Play is not ordinary life because it has a specific time, when it is typically repeated, and place (e.g., playground). "This is the third characteristic of play: its secludedness, its limitedness. It is "played out" within certain limits of time and place. It contains its own course and meaning" (Huizinga, 1950, p. 9). This repetition of play during certain periods of time stays in memory; becomes tradition; is culture (Huizinga, 1950). From major modern sport events (e.g., Olympic Games, World Cup Soccer, The Super Bowl, Wimbledon) to archaic, ceremonial and celebratory dances (e.g., dances in Australian Aborigines, Ancient Mesopotamia, and Axial Ages I-IV) play is part of society and culture, which is repeated during certain periods of time and uses a specific space (playground) (Bellah, 2011; Huizinga, 1950).

\section{Play creates rules and order outside ordinary life}

Play creates rules and order to be followed within the playground and outside ordinary life, which makes play enjoyable and fulfilling (4th characteristic of play). In her Weblog, Mitchell (2018) writes:

"When we play, we are distinctly aware that what we are doing is not 'ordinary life', though we might mimic everyday activities. We inhabit a different 'mental world' where there might be consequences to what we are doing, but those consequences usually adhere to different rules. This is one of the main reasons why play can be so satisfying, as we sometimes need to enter a space where the rules are different to everyday life - fairer or more clearly specified."

The rules of the game influence the playing experience in a unique and meaningful way for the player (e.g., the uncertainty of how the tennis ball will return to the server). The uniqueness of the playing experience reinforces its irreducibility - cannot be separated from the action (to-and-fro movement); thus, its close ties to aesthetics:

"Game rules normally determine what counts as victory or defeat. Thus, the quality of the player's experience depends, at least to some extent, on the structure of norms and resources that guide or organize her actions. Most games presuppose a player consciously aware of the game's objectives, equipment, and rules. To describe play is to describe its "meaningfulness" for the players. Playing is thus closely akin to aesthetics, in that experience is irreducible: it constitutes an essential aspect of the phenomenon" (Rodriguez, 2006, pp. 1-2).

Play demands perfection within an imperfect world; therefore, play's order links also to the field of 
aesthetics like in artistic (dance) expression. Huizinga (1950, p. 10) writes:

"Play has a tendency to be beautiful. It may be that this aesthetic factor is identical with the impulse to create orderly form, which animated play in all its aspects. The words we use to denote the elements of play belong for the most part to aesthetics, terms with which we try to describe the effects of beauty: tension, poise, balance, contrast, variation, solution, resolution, etc. Play casts a spell over us; it is "enchanting", "captivating." It is invested with the noblest qualities we are capable of perceiving in things: rhythm and harmony."

\section{Play creates tension, reflecting its unpredictability and moral value}

The key element of tension reflects the $5^{\text {th }}$ characteristic of play. Given that tension means uncertainty, humans and animals at play want to achieve something to release the tension: "baby reaching for a toy, pussy patting a bobbin, a little girl playing ball" (Huizinga, 1950, p. 11).

"To experience this sort of tension is to become invested in an outcome that has not yet been settled. It is always possible to ask: How will the game come out? The intensity of our investment in many games essentially depends on our consciousness that their outcome is not fixed in advance. Play offers the experience of the tension of having something at risk. The consciousness of risk, for instance, presupposes that the player cannot confidently anticipate the result of an action" (Rodriguez, 2006, p. 2).

Although play is outside morality as a good or bad action, the element of tension reflects a moral value to stick to the rules for fair play:

"the element of tension imparts to it a certain ethical value in so far as it means a testing of the player's prowess: his courage, tenacity, resources, spiritual powers, 'fairness'; because despite his ardent desire to win, he must still stick to the rules of the game... all play has its rules... as soon as the rules are transgressed the whole play-world collapses. The game is over. The umpire's whistle breaks the spell and sets 'real' life going again" (Huizinga, 1950, p. 11).
Based on MacIntyre's masterpiece, After Virtue (2015), fair play is part of good (or virtuous) practice whereby excelling at the game (internal good of the action) is of outmost importance and not winning by any means (e.g., cheating). In the following example, MacIntyre showcases the importance to strive to excel at the game of chess for its inherent value and not for external reasons. Excelling at a game requires respect for all its aspects, including rules, objectives, and other players, while cheating at any cost spoils the game.

"...if the child will play chess with me once a week I will give the child 50 cents worth of candy... if the child wins, the child will receive an extra 50 cents worth of candy. Thus, motivated the child plays and plays to win. Notice however that, so long as it is the candy alone which provides the child for a good reason for chess, the child has no reason not to cheat and every reason to cheat, provided he or she can do so successfully. But, so we may hope, there will come a time when the child will find in those goods specific to chess, in the achievement of a certain highly particular kind of analytical skill, strategic imagination and competitive intensity, a new set of reasons, reasons now not just for winning on a particular occasion, but for trying to excel in whatever way the game of chess demands. Now if the child cheats, he or she will be defeating not me, but himself or herself" (MacIntyre, 2015, p. 188).

The egalitarian element in play is part of its social aspect (social play), which is also apparent in animal play, reinforcing play's extension beyond the sphere of human life (Burghardt, 2005; Huizinga, 1950). Animals chase, wrestle, nibble, and nip without hurting each other (Burghardt, 2005). Large and physically strong animals do not take advantage of their superior physical strength and skills so that they can play with small and not as physically strong animals (Bekoff \& Pierce, 2009). When the chasing animal approaches the chased one the chased animal becomes the one that starts chasing even though it was never captured (Burghardt, 2005). De Waal (1996, p. 48) argues that strong rhesus monkeys of higher status know early on that "the fun will not last if they are too rough with a younger playmate." 


\section{Problems with/Critique of Exergaming}

To summarize, in the previous section we described five, non-reductive elements of true play as delineated by Huizinga (1950). Play is an intrinsic and freely chosen activity, which takes place outside ordinary life within a specific time and field. It has rules that need to be followed, reinforcing the unique experience of play and its close ties to aesthetics. Uncertainty creates tension, whereby the outcome of the game is unknown and instills the notion of fair play. In this section, exergaming will be contrasted with each of the characteristics of play, explaining why exergaming is not 'fun' and therefore why it consistently fails or fails to live up to its expectations.

Play is non-materialistic, irrational, and serves no biological purpose. It attracts the player because of the experience it can afford and not for the achievement of some rational, measurable goal like finding a way to relax or increase skills. On the contrary, exergames - played on such consoles as Nintendo, Xbox, and PlayStation - are utilitarian in nature with the main goal being to increase measurable exercise outcomes like increased steps taken, energy expended, and weight loss. This contradicts true play, which is devoid of purpose; a highly enjoyable activity as an end in itself. In play, it is the process that counts - the game itself - and not a biological outcome (Huizinga, 1950). The concept of exergaming belongs to function-centered theories, whereby the goal is to meet a certain measurable function to justify its action. In this technological and instrumental era of play, the player and game itself are objectified and their worth counts as long as measurable outcomes are achieved (e.g., taking 10,000 steps per day or losing 1-2 lbs. per week) in order to decrease obesity and mortality rates as expected by the Centers for Disease Control and Prevention (Kosma \& Buchanan, 2018, 2021). The importance of specific ends is pre-determined by experts (e.g., exercise promoters and the fitness digital industry), and a number is placed on them. The purpose of exergaming - to lose weight - is external to its engagement. Exergaming is functional designed for its biological benefits, and as such, weight loss can be achieved through many alternative means, and hence, it losses its internal meaning (for the experience in itself). "The lived quality of play cannot be captured by the vocabulary of mechanical motion. To say that play is "meaningful" is to say that, in virtue of its essential nature, it resists quantitative measurement and mechanical explanation" (Rodriguez, 2003, p. 3; emphasis added). The lack of the play element in exergaming is probably the reason for their lack of success - utilitarian success (goal) by increasing fitness levels to lose weight. For example, exergames have not exhibited the gateway effect to habitual physical activity, free play, or long-term exercise participation (Baranowski, 2017; LeBlanc et al., 2013; Staiano et al. 2017).

Another characteristic of play that emphasizes its free, enjoyable, and intrinsic nature is the fact that it takes place outside ordinary life in an imaginary and creative world. This is not the case with exergaming. Screen use is incorporated in almost all functions of life, including work, public education, and entertainment (White, 2004). Therefore, one is to wonder if being trapped in a room, behind a screen trying to lose weight is indeed an activity outside ordinary life or a drudgery that limits human freedom, imagination, and creativity (White, 2004). Exergaming is not an escape from the routine; it is the routine. Corporate giants in the highly profitable digital fitness industry have made exergaming easily accessible in smartphones, computers, and consoles (Kosma \& Buchanan, 2018; Resnick, 2012). However, the constant pressure to increase fitness and lose weight is not play nor is it a path to happiness and well-being. In his 2012 Harvard Health Letter, Resnick (p. 1) advises: “...don't let exergames nudge aside your participation in "real" sports and recreational activities. In terms of energy expended and pure enjoyment, the real things are bound to be more healthful and rewarding than electronic simulations."

The third characteristic of play - its repetition during certain time periods within a specified playground - has strong ties to culture and tradition. Sport events (e.g., Olympic Games) and dance festivals take place at certain time periods within a specified field. They are part of culture and tradition attracting spectators locally, nationally, and/or internationally. This is not the case with exergaming, which are highly individualistic in nature to determine when to be played and by whom. They do not link to cultural rituals and the excitement of anticipation. The initiation of ritual play places ordinary life at a standstill and involves whole communities and societies.

The fourth characteristic of play is its orderly fashion and the rules to be followed. The rules of the game are fairer than the experiences of ordinary life; 
thus, true play is enjoyable and an escape from the routine. It links to the orderly fashion of aesthetics, like dancing and theatrical performance, and its elements, such as beauty, creativity, rhythm, and harmony (Huizinga, 1950). Playful artistic expression via dancing and physical theater is irreducible, offering unique experiences and sensations, such as elation, flow, ecstasy, strength, vigor, rhythm, and harmony. These physical and emotional sensationsexperiences are inseparable from the action of performative play. The whole experience is immensely enjoyable - action for its own sake (Kosma \& Erickson, 2020a, 2020b; Kosma et al., 2020, 2021). This is in direct contrast with exergaming, which is utilitarian in nature and function oriented, in that there is reducible purpose-goal that needs to be measured: identify biological functions, such as increased fitness levels and loss of weight (Kosma \& Buchanan, 2021).

The orderly fashion of play links to its tension $\left(5^{\text {th }}\right.$ characteristic of play), which reinforces its irreducibility: the outcome of play is unpredictable and unexpected; it creates tension. The unpredictably unique experience in true play drives the player into the game and makes the game attractive (Gadamer, 1975/2012; Huizinga, 1950). The whole experience of play is of outmost importance, including its inseparable and complex outcome - it cannot be defined or measured by summing it up to some value (MacIntyre, 2015). By contrast, in exergaming, the whole emphasis is on the outcome that must be known and measured: increase number of steps, energy expenditure, and/or decrease number of pounds.

Tension also links to fair play - virtuous practice and the need to adhere to the rules of the game, substantiating its egalitarian nature. Good practices and their internal goods are inseparable, and they are good for whole communities, not only individuals; thus, they are objectively valued (MacIntyre, 2015; Wolf, 2010). A justly winning soccer team is a result of fair play, team play, hours and hours of practice, respect for one another, and wisdom in using practice time efficiently without abandoning family and friends. Such a just process will be essentially and symbolically valued by whole communities, who will celebrate the importance of leading an honest and dignified life, not only for soccer but also for other practices. The virtuous practice of the soccer team will be looked upon by communities within and outside sports. Contrary to exergaming, virtuous practices like fair play - and their integral good ends are incommensurable; a numerical value cannot be placed on them (to justify e.g., good soccer play) because they are qualitatively distinct - they are not a summable unit. Wisdom, justice, dignity, happiness, and excellence cannot be measured; they can only be experienced and felt. Although there cannot be an agreement on the specific content of virtuous practices, they are well-known within societies, valued, and can serve as symbols-ideals to look upon for the continuance of good practices (MacIntyre, 2015; Sayer, 2011; Wolf, 2010). When the goal is to obtain a certain value to measure virtues (e.g., excellence at soccer), then the process of good practice is at risk (MacIntyre, 2015; Smart \& Williams, 1973; Wolf, 2010).

The utilitarian nature of exergaming places the good nature of exercise at risk. There is no inherent value in the activity and its unique experiences as an end in itself; there is just digitized information regarding the direction of exercise levels - going up or down. If the objective goal is not achieved (e.g., increased number of steps, energy expended, or rapid weight loss), then the experience of play has failed; the virtual game is over. How can obsession with achieving measurable outcomes be fun, enjoyable, and a meaningful way to lead the good life? Although exergaming is advertised as a way to immerse in extraordinary, fantastical, and nearly out-of-space experience within virtual worlds, this new form of play reality extends the pressures, stresses, and burdens associated with having to meet biological and social needs like losing weight and achieving unrealistic body ideals (e.g., toned, thin, and firm female figures; Segar, Spruijt-Metz, \& Nolen-Hoeksema, 2006). Exergaming also requires screen viewing. Excessive screen use links to e-addiction, mental health problems like depression and anxiety, and asocial behavior (Dangkrueng et al., 2013; Kosma \& Buchanan, 2018, 2019; Kuss et al., 2014). The negative effects of excessive screen use have been currently put to the test due to the Covid-19 pandemic. Specifically, in a UK study it was shown that increased daily screen time because of Covid-19 linked to poor mental health (high depression and anxiety levels) among adults (35-64 years old) (Smith et al., 2020). Coupled with social isolation, increased childcare demands and job losses (especially for women), and Covid-19-related sickness and/or death, this pandemic has caused serious mental health problems, including increased anxiety and depression levels (especially among women), suicides (especially among African 
Americans), and suicide contemplation (especially among young adults - aged 18-24 years) (Haseltine, 2020).

According to the non-reductive elements of play by Huizinga (1950), this paper provides a unique analysis on how the engineered and instrumental design of exergaming is not play. Investing in utilitarian ways to make exercise playful and fun has not achieved its very goal; thus, such approaches need to be questioned for future use. Instead, physical activity experts need to rely on the elements of the true nature of play when they design physical activity programs. Physical activity is inherently playful; thus, in exercise programs the emphasis should be on the felt and unique experiences playful movement can afford, including artistic expression, dance, and recreational games at schools, neighborhoods, and local parks. Playful movement is undertaken for its own sake and not for any biological or social purpose. Physical activity experts need to understand that emphasizing measurable, virtual exercise outcomes does not lead to playful and enjoyable long-term physical activity participation. It is time to restore play as an integral part of leading well-balanced lives.

\section{Summary and Conclusion}

After showcasing the difficulty to clearly and specifically define and structure the concept of play, we drew on Huizinga's (1950) masterpiece, Homo Ludens, to holistically detail the main non-reductive elements of true play. Specifically, play is a freely chosen and enjoyable activity as an end in itself. It is devoid of purpose and has no biological function. It extends beyond the domain of human rationale and becomes attractive because of the unique experiences it can afford - it is part of human nature. It takes place outside ordinary life and can rise to levels above seriousness like in aesthetics. It is performed at a certain time and place; a ritualistic process, including the excitement of its anticipation and unique experience. Play has rules and order that need to be followed like in aesthetics (dance and theater). Its unique, irreducible, and unpredictable outcome links to tension and the value of the inherent nature of play and fair play. Fair play is a virtuous practice that can be looked upon by whole communities. We then contrasted the characteristics of true play with exergaming, showcasing that exergaming does not meet the elements of true play; thus, it fails to live up to its expectations. It is function centered and utilitarian in nature emphasizing reducible and measurable outcomes like increased fitness, weight reduction, and psychological health. In this technological era, the goal of the highly profitable digital fitness industry is to bring utility to play. Manipulating the masses to undertake a virtual workout - exergaming - to meet certain national standards is not play; rather, it can turn into drudgery with damaging mental health effects. When movement becomes an unpleasant workout to achieve measurable, objectified outcomes, people fail to enjoy the experience of play for its own sake. They fail to immerse into its magical world and be creative and imaginative. It is time to return to our roots and rejoice real play within our communities as an end in itself, which is part of human existence and consciousness.

\section{Conflict of Interest}

The author does not report any conflict of interest related to this paper.

\section{References}

Aarseth, E. (2017). Just games. Int J Comput Games Technol, 17(1), 1 .

Bakhtin, M. M. (1981). The dialogic imagination: Four essays. University of Texas Press.

Baranowski, T. (2017). Exergaming: Hope for future physical activity? Or blight on mankind? J Sport Health Sci, 6(1), 44-46.

Bekoff, M., \& Pierce, J. (2009). Wild justice: The moral lives of animals. Chicago University Press.

Bellah, R. N. (2011). Religion in human evolution: From the Paleolithic to the Axial Age. The Belknap Press of Harvard University Press.

Benzing, V., \& Schmidt, M. (2018). Exergaming for children and adolescents: Strengths, weaknesses, opportunities and threats. Journal of Clin Med, 7(11), 422.

Berlyne, D. E. (1960). Conflict, arousal, and curiosity. McGraw-Hill Book Company.

Bogost, I. (2007). Persuasive games: The expressive power of videogames. Cambridge. The MIT Press.

Burghardt, G. M. (2005). The genesis of animal play. Testing the limits. The MIT Press. 
Csíkszentmihályi, M. (2008). Flow: The psychology of optimal experience. Harper Collins Publishers.

Dangkrueng, S., WannaUeumol, T., Yodming, P., \& Sirithongthaworn, S. (2013). Relationships between Internet addiction and loneliness, and Internet addiction and teenage social skills: A case study of Mathayom Suksa students in the Northern Region. International Journal of Child Development and Mental Health, 1(2), 26-30.

De Waal, F. B. M. (1996). Good natured: The origins of right and wrong in humans and other animals. Harvard University Press.

Gadamer, H-G. (1989). Truth and method. Crossroad.

Gadamer, H-G. (2012). Truth and Method (2nd edition) (J. Weinsheimer \& D. J. Marshall, Revised Trans.). Continuum International Publishing Group. (Original work published 1975).

Goffman, E. (1974). Frame analysis: An essay on the organization of experience. Northeaster University Press.

Handrigan, J. P. (2013, April 14). Nintendo's disruptive strategy: Implications for the video game industry. Asia Case Research Center: The University of Hong Kong. http://secure.expertsmind.com/attn_files/1660_cobnintendos\%20disruptive\%20strategy.pdf

Haseltine, W. A. (2020, November 24). The mental health toll of COVID-19: Some American communities carry a disproportionate burden. Psychology Today. https://www.psychologytoday.com/us/blog/bestpractices-in-health/202011/the-mental-health-tollcovid-19

Henricks, T. (2008). The nature of play: An overview. American Journal of Play, 1(2), 1-24.

Huizinga, J. (1950). Homo Ludens: A study of the playelement in culture. Roy Publishers.

Khalili-Mahani, N, Smyrnova, A., \& Kakinami, L. (2019). To each stress its own screen: A cross-sectional survey of the patterns of stress and various screen uses in relation to self-admitted screen addiction. J Med Internet Res, 21(4), e11485.

Kosma, M., \& Buchanan, D. R. (2018). “Connect," log it, track it, go! Techne-not technology-and embodiment to achieve phronesis in exercise promotion. Quest, 70 (1), 100-113.

Kosma, M., \& Buchanan, D. R. (2019). Aspects of depression among socio-economically disadvantaged African American young adults. Int $Q$ Community Health Educ, 39(4), 199-207.

Kosma, M., \& Buchanan, D. R. (2021, Key Book Article). Reconsidering the push for digitized physical activity education in lieu of the intrinsic value of embodied action (pp. 63-71). In C. Steinberg \& B. Bonn (Eds.), Digitalisierung und Sportwissenschaft [Digitization and Sports Science]. Academia. www.nomosshop.de/isbn/978-3-98572-002-6

Kosma, M., \& Erickson, N. (2020a). The embodiment of aerial practice: Body, mind, emotion. J Dance Educ, 20(4), 224-233.

Kosma, M., \& Erickson, N. (2020b). The love of aerial practice: Art, embodiment, phronesis. International Journal of Kinesiology and Sports Science, 8(1), 14-25.

Kosma, M., Erickson, N., Savoie, C. J., \& Gibson, M. (2020). The effectiveness of performative aerial practice on mental health and the love of movement. Advance online publication on 7/3/20. Res Dance Educ, https://doi.org/10.1080/14647893.2020.1784868

Kosma, M., Erickson, N., Savoie, C. J., \& Gibson, M. (2021). Skill development vs. performativity among beginners in aerial practice: An embodied and meaningful learning experience. Int $Q$ Community Health Educ, 41(2), 173187.

Kuss, D. J., Griffiths, M. D., Karila, L., \& Billieux, J. (2014). Internet addiction: A systematic review of epidemiological research for the last decade. Curr Pharm Des, 20, (25), 4026-4052.

LeBlanc, A. G., Jean-Philippe C., McFarlane, A., Colley, R. C., Thivel, D., Biddle, S. J. H., Maddison, R., Leatherdale, S. T., \& Tremblay, M. S. (2013). Active video games and health indicators in children and youth: A systematic review. PLoS One, 8, e65351.

Lloyd, R. (2016). Becoming physically literate for life: Embracing the functions, forms, feelings and flows of alternative and mainstream physical activity. J Teach Phys Educ, 35(2), 107-116.

MacIntyre, A. (2015). After virtue: A study in moral theory. ( $3^{\text {rd }}$ edition). University of Notre Dame Press.

Merleau-Ponty, M. (2014). Phenomenology of perception (D. A. Landes, Trans.). Routledge. (Original work published 1945).

Mitchell, L. (2018, December 19). Seriously learned: Dr. Laura Mitchell is... seriously learned: Are we Homo Ludens? Huizinga's 5-point definition of play. https://drlauramitchell.com/2018/12/19/definingplay/

O'Leary, K. C. O., Pontifex, M. B., Scudder, M. R., Brown, M. L., \& Hillman, C. H. (2011). The effects of single bouts of aerobic exercise, exergaming, and videogame play on cognitive control. Clin Neurophysiol, 122(8), 1518-1525.

Pedersen, S. J., Cooley, P. D., \& Cruickshank, V. J. (2017). Caution regarding exergames: A skill acquisition perspective. Phys Educ Sport Pedagogy, 22(3), 246-256. 
Paw, M. C. A, Wietske, J., Vaessen, E. P. G., Titze, S., \& van Mechelen, W. (2008). The motivation of children to play an active video game. J Sci Med Sport, 11, 163-166.

Resnick, L. (2012, March 08). Exergames: A new step toward fitness? Harv Health Lett. https://www.health.harvard.edu/blog/exergames-anew-step-toward-fitness-201203084470

Rodriguez, H. (2006). The playful and the serious: An approximation to Huizinga's Homo Ludens. The International Journal of Computer Game Research, 6(1), 1-18.

Sall, A., \& Grinter, R. E. (2007). Let's get physical! In, out and around the gaming circle of physical gaming at home. Computer Supported Cooperative Work, 16(1), 199-229.

Sartre, J-P. (2003). Being and nothingness: An essay on phenomenological ontology (H. E. Barnes, Trans.). Routledge. (Original work published 1943).

Sayer, A. (2011). Why things matter to people: Social science, values and ethical life. Cambridge University Press.

Segar, M., Spruijt-Metz, D., \& Nolen-Hoeksema, S. (2006). Go figure? body-shape motives are associated with decreased physical activity participation among midlife women. Sex Roles, 54(3), 175-187.

Sheets-Johnstone, M. (2003). Child's play: A multidisciplinary perspective. Human Studies, 26(4), 409-430.

Smart, J. J. C., \& Williams, B. (1973). Utilitarianism for and against. Cambridge University Press.

Smith, L., Jacob, L., Trott, M., Yakkundi, A., Butler, L., Barnett, Y., Armstrong, N. C., McDermott, D., Schuch, F., Meyer, J.,
López-Bueno, R., Guillermo, F., López, S., Declan, B., \& Tully, M. A. (2020). The association between screen time and mental health during COVID-19: A cross sectional study. Psychiatry Res, 292, e113333.

Staiano, A. E., Beyl, R. A., Hsia, D. S., Katzmarzyk, P. T., \& Newton Jr., R. L. (2017). Twelve weeks of dance exergaming in overweight and obese adolescent girls: Transfer effects on physical activity, screen time, and self-efficacy. J Sport Health Sci, 6(1), 4-10.

Statistica. (2020). Digital Market Outlook: Fitness: Worldwide. Retrieved June 10, from https://www.statista.com/outlook/313/100/fitness/w orldwide

Tchang, B. G., Saunders, K. H., \& Igel, L. L. (2021). Best practices in the management of overweight and obesity. Med Clin North Am, 105(1), 149-174.

Thompson, W. R. (2018). Worldwide survey of fitness trends for 2019. ACSMs Health Fit J, 21(6), 10-19.

Trust for America's Health. (2020). The state of obesity: Better policies for a healthier America. Retrieved June 25, 2021, from https://www.tfah.org/reportdetails/state-of-obesity-2020/

Vygotsky, L. S. (1978). Mind in society: The development of higher psychological processes. Harvard University Press.

White, C. (2004). The middle mind: Why Americans don't think for themselves. HarperCollins Publishers, Inc.

Wolf, S. (2010). Meaning in life and why it matters. Princeton University Press. 